\title{
Culture Denatured OR NATURE DECULTURED
}

Peter Ampt and Linda Raymond

The Australian Museum is a museum of both natural science and cultural heritage. As an institution we find this quite a challenge, both in our communication with our audiences and in our internal debates about who and what we are. In the area of natural science we feel quite confident in our adopted role in the community. With our vast collections of specimens and reputation for scholarly research, the Australian Museum assumes what Ellen Futter, President of the American Museum of Natural History, NY, describes as 'a stewardship of the natural world' (Futter, 1997, p40). Our mission explicitly states an intention to engage in and influence public debate. We feel this mission with a certain sense of urgency based on our knowledge of what is happening to the natural world. We acknowledge our role in bringing about a change of attitude in our visitors, and have generally sought to do this by presenting to our audiences the objective and value-free 'science' of nature while simultaneously using that science to support a point of view.

However, more recently, the Australian Museum has recognised that if exhibitions are to encourage audiences to form the emotional bond with nature that leads to attitudinal change, we need to provide more emotional experiences and have human points of entry. We are recognising that our own notions of culture and nature and their representation in exhibitions need to broaden. This shift away from just presenting scientific information as a means of informing our audiences has been reflected in our recent exhibitions: Spiders, Thirst and Biodiversity. In this paper we briefly examine some of the philosophical issues that underlie this shift. We will examine the nature of science and explore the relationships between science, nature and culture. Finally, we will use these concepts to analyse the very successful Spiders! exhibition.

As we continue to question how we make exhibitions, one of the primary underlying issues which continually arises is the relationship between Nature and Culture and how we express that relationship through exhibitions. In fields other than museology, there is a great deal of 
debate about this relationship, particularly among anthropologists, sociologists and others engaged in the social sciences. Increasingly it is understood that;

The 'myth' of nature is a system of arbitrary signs, which relies on a social consensus for meaning. Neither the concept of nature nor that of culture is 'given', and they cannot be free from the biases of the culture in which the concepts were constructed. (MacCormack 1980, p6)

The corollary to this is that culture itself is a process by which we react to our environment and is determined by nature. Thus the relationship between nature and culture is complex and dynamic and it follows that no one culture has a monopoly on a 'true' view of nature.

At the Australian Museum, the authors believe, this is not altogether well understood and at times positively contentious. Where it is understood it is not made explicit to our audiences. Neither is cultural diversity understood in the broad terms which allow us to think beyond mere tokenism. The representation of cultural diversity in exhibitions is not simply a matter of including a few cultural artefacts from a range of different ethnic groups which might have some reference to the exhibition theme. What is required is to think beyond our own cultural preconceptions to understand the ways in which those preconceptions are implicitly supported by everything from the very structure of exhibitions to the choices we make regarding exhibition themes. It requires us to be aware of the cultural biases inherent in even the kind of science we display in our exhibitions.

\section{THE IDEA OF SCIENCE}

Let's take as our starting point the very idea of science. Science is knowledge and process, fact and opinion. Much of the dilemma facing museum exhibition teams is understanding this and making explicit in exhibitions which is which. It encompasses great diversity that is rarely communicated to museum audiences. The tendency is to present science in stereotypically narrow and homogenous ways both in its representations of itself and its relationship to other knowledge systems.

Firstly, science is a complex human activity that not only involves curiosity, ideas, hypothesising and experimentation, but also debate, disagreement, competition, commerce and ambition. Different scientists work on different projects and at different levels and express points of view that relate to their own worldview. A taxonomist, an evolutionary biologist, an ecologist would each provide different emphases in a public program and bring their own cultural baggage to any exhibition project team.

Secondly, science is not just undertaken by specialists but also by people without formal scientific training e.g. processing of toxic plant materials into food by Indigenous Australians, potato cultivar selection in South America, rice cultivar selection in Asia and numerous other examples of indigenous technical knowledge. In addition to which there are notable historic figures in science such as genetics pioneer Gregor Mendel.

Thirdly, scientific knowledge does not necessarily represent truth but is more accurately a model that is accepted by the scientific community of the time. Thus 
scientific knowledge is subject to change. As Kuhn (1962) wrote in his book The Structure of Scientific Revolutions,

An apparently arbitrary element, compounded of personal and historical accident, is always a formative ingredient of the beliefs espoused by a given scientific community at a given time. (p4)

Kuhn goes on to say that

Normal science... often suppresses fundamental novelties because they are necessarily subversive of its basic commitments. (p5)

This may continue until these novelties become more than the exception, when a 'scientific revolution' may take place in which scientific traditions are shattered and replaced by a new set of commitments.

This aspect of science, widely accepted by scientists, is rarely displayed in public programs. Rather, there is a tendency to present one coherent and seamless perspective, smoothing down the conflicting views and controversies that arise as part of the scientific process. We are concerned to maintain a sense of authority over the material, arguing that audiences may be misled or confused by a display of diverse scientific opinions,

...giving the impression that the results are too unsure or trivial to be worth considering. (Sudbury, 1993, p28)

One of the underlying reasons for such an impression may be a lack of familiarity with the processes of science. Science has its own culture into which people need to be initiated if they are to feel comfortable, to understand and to participate. This culture is expressed in a hierarchical arrangement of information, a dependence on the visual, and specific kinds of visuals such as photographs, diagrams, maps and charts, as well as a heavy dependence on text and text of a technical nature. People identify these genres in exhibitions without necessarily having the training to read them, exacerbating their feeling of exclusion from science and militating against their participation in it.

In addition, scientific insights and actions are juiced with passion, serendipity, imagination and intuition. But we take these elements and express them in the passive voice, embed them in specialised technical language and the passion is lost. By excluding these elements from our exhibition repertoire we close off potential avenues to deeper insights for our audiences.

Finally, the science in evidence in many museum exhibitions is largely a product of western industrial cultures. This science sees itself as definitional of 'knowledge, rationality and objectivity' (Watson-Verran and Turnbull, 1995, p16). Such a view locks out the possibility of representing other knowledge systems, which in turn excludes a diversity of cultures from representation.

The dominant view of science, at least among many scientists and much of the general public, is that it is set apart from culture, indeed 'transcends' it. Science is universal, culture is 'localised strategies for making sense'. (Franklin, 1995, p174)

But this is to ignore the ways in which science is consistently negotiated with culture. It is both an aspect of culture and an influence upon culture, in a dynamic 
6 interplay in which neither can be regarded as separate from the other. Andrew Ross, suggests in The Chicago Gangster Theory of Life: nature's debt to society, that

Scientific ideas are as much a part of the dynamics of society as any other aspect of culture. The way we think about the natural world has more to do with our social world than anything else. (Ross, 1994, p15)

Western science is in reality as much a local knowledge system as any other. Different cultures have different explanations of origins and processes in nature, which exist quite apart from and parallel to western science. If we are to acknowledge these systems in our exhibitions, we must respect them on their own terms.

We cannot step outside our minds to see if our ideas correspond to Reality with a capital R. Hence we cannot know the Truth with a capital T. No worldview is epistemologically privileged in the sense that it alone is certifiably true and all others are false. It follows that traditional cultural worldviews cannot be said to have a share in the truth only to the extent that they jibe with science. (Callicott, 1997, p190)

We must recognise the validity of alternative systems of organising and understanding the world and value the possibilities of real insights and different perspectives denied through dominant western patterns of thought.

One of the consistent characteristics of alternative worldviews is their capacity to consider the world and the place of humans within it in a wholly integrated way. Helen Watson-Verran and David Turnbull have presented a case study of the Yolngu people of the northwestern Northern Territory that enunciates this idea. They write:

In science, nature and society are taken as quite different than each other and different than knowledge...This is in stark contrast to Yolngu knowledge, which... does not see nature-society-knowledge as constituted of distinct and different sorts of things. (Watson-Verran and Turnbull, 1995, p134)

Thus science and culture are wholly integrated, which while not uncommon in non-western knowledge systems, highlights another attitude prevalent in museums, which ultimately fails us. We continue to think in terms of 'science' exhibitions and 'cultural' or 'social history' exhibitions fearing that any blending of the two would confuse audiences and devalue the 'truth'. In reality,

for the visitor, an object of interest provokes many questions which are cross-disciplinary; he or she is probably not interested in our museological boundaries. (Heumann Gurian, 1991, p186)

By maintaining the artificial boundaries between science and culture we are closing out a whole of range of options for reaching our audiences. We want to provide our audiences with fresh insights, new and startling juxtapositions of ideas about nature to excite them with the 'ah!' factor, the trigger to a change in attitude. We will now apply some of these ideas to the Spiders! exhibition. 


\section{ANALYSIS OF THE SPIDERS! EXHIBITION}

The success of this exhibition took many people by surprise. Visitor numbers were considerably higher than expected, resulting in big crowds and queues and increased revenue. The numbers continued throughout the exhibition time at the Australian Museum, indicating that considerable 'word-of-mouth' promotion was happening due to satisfied visitors. This success continued in Melbourne.

Visitor evaluation studies done by the Museum's evaluation unit have shown that visitors were not only happy with the exhibition, but they stayed in there a long time (much longer than similar exhibitions in the past) and actually learnt something. Exhibition staff also reported some pretty amazing experiences with spiderphobic people confronting, and in many instances working to overcome their fear of spiders.

Many of us speculated about what it was that made the Spiders! Exhibition so successful. The purpose of this section of our paper is to analyse the experience according to the arguments that we have already presented for representing natural and cultural diversity. The comments that we make are not intended as criticisms of any of the team members, but simply a product of the authors' reflection on the process.

\section{Were diverse relationships between people} and nature represented in the exhibition? The voice of the Museum science was probably heard loudest and the cultural aspects of spiders were peripheral. Stories, images, objects and history concerning spiders from various cultures, spiders in popular culture and live tarantulas (movie stars of the spider world) were in a section at the end of the exhibition called 'Fear, fascination and fate'.

Interestingly, the team had, in the early stages of the project, intended to incorporate social and cultural voices throughout the exhibition. So why were cultural voices placed near the end of the exhibition, a placement which may have contributed to fewer people taking note of them? And why were some cultural materials omitted? (Please note that decisions were also made to omit biological content)

There are several reasons why this occurred. Firstly, there were particular problems with some of the cultural materials. It was difficult to clarify which cultural objects could be used, and how to display them sensitively. Other cultural information existed only as text and the team were determined that objects and/or interactives should accompany text. As a result, the range of materials we had to choose from became somewhat narrow. Secondly, the team decided to build a cultural story around the live exotic tarantulas, which were contextualised as 'the movie stars of the spider world'. The team decided to make a feature of them near the end of the exhibition. This was a deliberate strategy to finish the exhibition on a high note, and it worked successfully.

Thirdly, as often happens, there was a rush to finish the exhibition. There were several reasons for this:

- the schedule was tight from the outset, leaving little room for flexibility;

- many components took longer than we had planned. One example of this was text production. The aim was to achieve 
8 both accessible, readable text and scientific accuracy. This was a very important process, and it took time.

Many decisions were made about locating and omitting both biological, social and cultural material (for reasons of design, practicality and cost) in the hectic last months of exhibition preparation when lengthy deliberations were not possible.

Having already decided to place most cultural material together, there were discussions during the later stages about placing some other material throughout the exhibition. One particular instance remains firmly etched in memory and it concerned spider origins. The scientific story was told with text, a time line and a diorama. An Indigenous Australian group had a very different story that goes like this:

How spiders came to be
and why they live in dark caves:
an Aboriginal Story

A beautiful and promiscuous woman called Jitae was a member of the Wandi, a group of ancestral spirits who lived near the country of the Muripatha (Port Keats, Northern Territory). She slept with some of the men but rejected others, leading to jealousy and mistrust amongst the Wandi.

Jitae and her supporters were chased across the land by their enemies and after much fighting and killing, tried to escape by building a mountain that reached into the sky country. But before they could reach the top, Jitae grew tired and could not go on. So she and her followers turned themselves into spiders and hid in the deep dark cave near the top of the mountain.

Their enemies found nothing, and to this day spiders have multiplied and spread to dark caves and other sheltered places.

(Summarised from Allen 1975)
This story was left out because the team decided it was out of context with the scientific origin story, and, since we did not have an authentic image to go with it, the story would have been a 'dead' text panel.

Another example was an Indigenous Australian cave painting of an Archer Fish 'shooting' a spider. We discussed putting this in the section on spider survival, in the process valuing indigenous expertise and knowledge at the same time as illustrating spider predators. But instead we decided to put it in the social and cultural 'section' because, despite being a beautiful illustration of spider being eaten, spiders are not regular prey of Archer Fish, and it didn't fit the more scientific style of the spider survival section.

Whilst these decisions were made by the whole team for good reasons, the net effect was to reduce the amount and impact of the cultural material.

How were preconceptions about science dealt with in the Spiders! exhibition?

In the opinion of the authors, the scientific perspective of the written content was primarily reductionist and positivist. Interestingly, this was influenced by the need for brevity and clarity in the text. As a result, alternative explanations were often lost. Conflicting viewpoints were presented in several instances despite Arachnology not being a particularly controversial area.

In terms of branches of science, spider taxonomy and relationships, evolution, distribution and speciation, ecology, arachnidism, physiology, anatomy and behaviour were all covered, with spider behaviour given greatest emphasis.

Scientific technicality did not dominate 
the text. This was largely due to the attention paid to text by the scientist and the text editor that was mentioned earlier. Biological names and scientific classification appeared rarely in upper levels of text, but were deliberately included in object/image labels. As a result, people were able to access more detailed information about an object, specimen or image if they desired. This also allowed people to view the exhibition at the level that suited them.

There was also a deliberate attempt to show science as a process, not just knowledge. This was a feature of Spiderlab, a place where people could get close to spiders and talk with education and scientific staff. Spiderlab also helped break down scientific stereotypes. Staff engaged in dialogue with visitors, which was not authoritarian but negotiated. Visitors had the opportunity to ask questions and could dictate the level of interaction, often bringing in spiders and information to add to the dialogue. Visitors were encouraged to take part in 'scientific' activities that helped to demystify science - they could see that these activities were similar to everyday activities such as sorting, observing and categorising.

According to the people who worked there, Spiderlab was spectacularly successful at bringing people closer to spiders, even self-confessed arachnophobes. In a focus group a staff member said:

They came to face their fear of spiders - we observed changes in behaviour which suggested that many worked through their fears, changing their views and feelings about spiders while they were in Spiderlab.
What other voices and points of view were incorporated?

In terms of content, the scientific voice did dominate. This was appropriate, given the subject matter. However, the exhibition didn't feel like a traditional science exhibition to our visitors. This had a lot to do with the use of live spiders, design elements, the way the team dealt with technicality and the attention paid to the way people learn through the interpretive strategies employed. But this was also due, in some part, to the incorporation of other voices in the exhibition.

Visitor research, in the form of frontend evaluation, was an important component in the development of the exhibition. This research confirmed and informed the team's view, and helped contribute to the exhibition structure.

For example, in the front-end evaluation we found a strong link between fear and fascination - most people who said they were fearful of spiders were also fascinated with them. This, together with historical and cultural information about spiders, helped the team with the opening words of the exhibition:

Spiders have fascinated and frightened people for centuries.

Why do spiders evoke such strong feelings?

Come and look deeper into their world.

This link between fear and fascination gave us the liberty to use people's fear playfully as a drawcard without sabotaging our message of 'few spiders are dangerous' eg. garden shed, live exotic tarantulas, spiders in the movies and live dangerous spiders.

In generating the storyline for the exhi- 
10 bition, the team used the voices of visitors from front-end evaluation to inform their choices. The storyline was told through the section headings:

\section{Spiders are everywhere \\ Few spiders are dangerous \\ A spider's toolkit \\ A spider's life \\ Fear, fascination and fate \\ and on text panels, for example \\ hairy doesn't mean scary.}

The spiders themselves seemed to show through - through images, videos, specimens, but more spectacularly through the live spiders. Live spiders were throughout the exhibition, but were particularly a feature of the tarantula room and Spiderlab, where visitors were encouraged to see them up close making egg sacs, feeding and making webs.

As previously mentioned, spider stories from other cultures, history, and popular culture (as well as tarantulas, the movie stars of the spider world) were included in the section entitled 'Fear, fascination and fate'. There were more stories left out than were finally included, and the criterion for inclusion was largely dictated by availability of objects and time.

One critical omission was an expression of the central position held by spiders in the belief systems of some human groups, because of the intricacies of spider behaviour and lessons humans can learn from them. What more dramatic way to lead people into a fascination with spiders than to show how other cultures have such profound respect and understanding of spiders to make them deities or weave them into creation stories. Unfortunately, the team wasn't able to research these areas thoroughly enough to include them.

\section{CONCLUSION AND STRATEGIES FOR ACTION}

This paper grew out of a frustration about the marginalisation of social and cultural material in many earlier natural science exhibitions and the narrow view of science often presented in them. The authors' opinion is that the Spiders! exhibition succeeded in redressing this in many but not all areas.

The integration of the visitors' voice, together with varied interpretive strategies and imaginative and sensible design provided visitors with multiple points of entry into the interesting and innovative content of the exhibition. The written content was expressed in an accessible and readable way. The use of live spiders and the mediation of the visitors' experience by staff in Spiderlab promoted a deeper appreciation of spiders. These factors have contributed significantly to the continued success of the exhibition.

By contrast, material that represented cultural diversity was not incorporated throughout the exhibition, but at the end of the exhibition, albeit for sensible reasons. Whilst many visitors found the material interesting, its location may have reduced its impact.

On reflection, we recognise that there are barriers that militate against the incorporation into natural science exhibitions of the plurality of meanings and relationships that exist between people and the natural world. Recognising these barriers is clearly more than just accepting that non-scientific perspectives have something 
to offer. It is also understanding the extent to which nature and culture are interdependent and the dominant role science normally plays in interpreting nature in natural science exhibitions. In order to offer our audiences the kind of profound and poetic experience that will lead to the change in attitude that is our mission, we suggest that exhibition project teams be aware that the following barriers may exist:

- what is practically achievable within time and budget constraints

- the view that scientific knowledge should be privileged over other forms of knowledge

- seeing science as objective and independent of culture

- taking an unrealistically narrow view of science

- the culture and technicality of science which obscures and/or prevents entry of people into scientific understanding of nature

- time and expertise to adequately research the social and cultural aspects of the topic.

As a follow-up to this paper and the subsequent feedback, we are in the process of preparing a set of guidelines that exhibition project teams may find useful or appropriate. At present, it is in draft form as a series of questions in three focus areas:

\section{To influence public opinion about the natural environment}

Does the exhibition provide opportunities for visitors to express and discuss their own construction of the information?
Are you appealing to peoples emotions?

Does passion, imagination and/or humour come through or is it embedded in technicality?

\section{To promote a broader view of science within the context of culture}

Are you being explicit about the scientific voice or voices being heard?

Are you including a diverse range of scientific disciplines and points of view?

Will you present scientific information as interpretation rather than truth?

Will you present scientific controversy where appropriate?

Are you promoting the understanding of science as a process?

Have you presented science together with other voices?

Are the scientific literacy demands of the exhibition appropriate for the audience?

\section{To represent the natural environment through many voices}

What resources are you committing to researching other voices?

Is the visitor's voice included and how is it used?

Are the voices of other groups heard through the exhibition?

Is cultural context taken into account and made explicit?

Who is being consulted?

Who will be contributing knowledge/ expertise?

Is a diversity of opinion being sought?

Please contact us if you want further information or wish to contribute to the guidelines. 
The authors wish to acknowledge the editorial input of Dr Mike Gray, the Head of the Spiders! team. However, the opinions expressed here are those of the authors.

This paper was presented at the CECA meeting in the ICOM General Conference, Melbourne, Australia Oct. 1998.

\section{REFERENCES}

Allen L A (1975): Time before morning: Art and Myth of the Australian Aborigines, Thomas Y Crowell Company, New York 1975

Callicott J B (1997): Earth's Insights: a multicultural survey of ecological ethics from the Mediterranean Basin to the Australian outback, University of California Press, Berkeley and Los Angeles 1997

Franklin S (1995): Science as culture, cultures of science, Annual Review of Anthropology, 24:16384, 1995

Futter E (1997): Biodiversity, Museum News November/December 1997

Heumann Gurian E (1991): Noodling around with exhibition opportunities, in Karp I and Lavine S D (Editors) (1991): Exhibiting Cultures: the poetics and politics of Museum display, Smithsonian Institution Press, Washington and London 1991

Kuhn T S (1962): The structure of scientific revolutions, Phoenix Books, University of Chicago Press, Chicago and London

MacCormack CP (1980): Nature, culture and gender: a critique, in MacCormack CP and Strathern M (Editors): Nature, culture and gender, Cambridge University Press 1980

Ross A (1994): The Chicago Gangster Theory of Life: nature's debt to society, Verso London 1994

Sudbury P (1993): Science by stealth, Museums Journal November 1993 